\title{
Self-Immolation in The Extinction of Menai by Chuma Nwokolo
}

\author{
ADAOBI NKEOKELONYE \\ Faculty of Modern Languages and Communication \\ University Putra Malaysia \\ dobymadu@gmail.com \\ HARDEV KAUR JUJAR SINGH \\ Faculty of Modern Languages and Communication \\ University Putra Malaysia \\ MOHD. ZARIAT ABDUL RANI \\ Faculty of Modern Languages and Communication \\ University Putra Malaysia \\ MANIMANGAI MANI \\ Faculty of Modern Languages and Communication \\ University Putra Malaysia
}

\begin{abstract}
This study explores the concept of self-immolation within the African literary space. It observes how people bear witness to express causes through protests, with their words, action and the self-application of lethal harm. With growing incidences of suicides around the world, self-Immolation remains peculiar generally for its politicization and likening to a sacrifice for a cause, drawing attention to social injustice and giving voice to acts of persecution which could have been voiceless. Although self-Immolation has gained interdisciplinary attention, there is an observable dearth of scholarship in the field of literature. In African literature, writers have adopted suicide as a way of dying for their characters; the much-celebrated work of Chinua Achebe gives credence to this. Studies exploring the underlying aetiology of self-inflicted deaths in novels remain sparse. In this study, we focus on The Extinction of Menai (2018) by Chuma Nwokolo, a contemporary African writer. Using the work of Emile Durkheim on Suicide as an operative framework, we explore incidences of self-inflicted deaths as a protest mechanism. We establish the use of suicide for protests by characters that cut across gender lines. We equally note the underlying cultural melody behind all acts of suicide witnessed in this novel by Chuma Nwokolo.
\end{abstract}

Keywords: Suicide; Self-immolation; African Literature; Chuma Nwokolo; Cultural Extinction

\section{INTRODUCTION}

Bravely and peacefully, Thich Quang Duc sits in a lotus position, doused in petrol, sets himself alight as he is enveloped in flames. The elderly Vietnamese monk leaves his words; a request that President Ngo Dinh Diem shows more kindness and tolerance towards his people, and that religious equality be enforced. Thich Quang Duc's 1963 self-inflicted death - as part of the Buddhists protest of their persecution by the South Vietnamese government - becomes a type specimen of self-immolation; a landmark in the global understanding of self-immolation and the study of it (Biggs 2006; Brown 1963).

Owing to the similarities of the ways of dying adopted by some self-immolators, the word self-immolation often invokes a self-inflicted death by burning or by fire. But this is less inclusive of other ways people have chosen to sacrifice their lives and bodies in protest of a perceived injustice. For the purpose of this study, we have adopted a definition of selfimmolation that does not specifically refer to the method of burning oneself to death, but as the broader definition of protest suicide. A relevant definition of self-immolation is offered by Biggs (2006) who defines self-immolation as the act of an individual killing himself or herself intentionally on behalf of a collective cause. It is characteristically marked by publicity in the 
sense that it is either performed publicly, or the message of the self-immolator is addressed to a public figure or the public (Biggs 2012). Self-Immolation is distinguishable from other acts of personal suicide: where a person inflicts death on his/herself for non-collective reasons, or suicide terrorism: where a person inflicts death on himself and others for reasons of faith or ideology. The underlying collective cause that self-immolators die for is what sets them apart from all other forms of self-inflicted death. To take one's life for a cause is therefore perceived as the most extreme of all forms of protest (Biggs, 2006).

Towards the end of 1960's, self-Immolation became a focus of academic study, gaining disciplinary attention in psychology, medicine and broader spectrums of profession like filmmaking and pacifism among others. With few exceptions, studies focused on self-immolation are lacking as it is largely unexplored within the field of sociology (Biggs 2006). Over the years, numerous publications on self-immolation in the field of social sciences have contributed extensively to the understanding of this concept. The concept has since been marked with studies of various incidences of it, some of which are modeled in similar ways with Thich Quang Duc, conducted in many countries across the world, across continents and across gender lines, amongst other stratification (Ahmadiet et al., 2008; Biggs, 2012; Makley, 2015; Shakya, 2012; Rommet et al., 2008).

In spite of the relevance of suicide death in global discourse of terrorism and psychology, the media attention on self-immolation, the governmental and more so scholarly interest it had garnered, a dearth of materials centering on this concept in the field of literature is observed. In the spaces of literary discourse, suicidal acts of characters have been highlighted in studies as affirmative acts (Krishnamurthy 2016; Ryan 2000). In African literature which is specifically the focus of this study, acts of suicides by characters are not found wanting. The renowned work of Chinua Achebe Things Fall Apart (2009) registers a suicide committed by the protagonist of the story Okonkwo. Studies on this incidence have often focused on the act as a tragedy. Reviews of Okonkwo's shocking suicide have been explored from diverse perspectives. Some have focused on aiding the understanding of his motive within the spaces of the Igbo culture (Ogbaa 1981). Others have interpreted Okonkwo's suicide as an act of affirmative act, a willful resistance rather than an act of shame and dishonor (Friesen 2006). The potentials of Okonkwo's suicide being an act of cultural protest against the encroachment of the western missionaries are plausible but remain largely unexplored.

In this study, we aim to explore the concept of self-immolation as it is represented in literature. Drawing on previous works on self-immolation, we extend its relevance to the field of literature, and specifically African literature. This study rests on the narratives of The Extinction of Menai by Chuma Nwokolo. It is selected for its relevance to the concept understudy. From his list of published works, The Extinction of Menai is selected for its projections of themes of suicide and other relatable acts. Characters in this novel represent ordinary people who have taken to defiance against the powers that be, by doing extra-ordinary things. The denial of their agency or perceived rights results in their choices of protest, and the adoption of suicide as a mechanism.

\section{THEORETICAL FRAMEWORK}

In this study, Emile Durkheim's (1951) theory of suicide serves as an operative framework and a useful start point. Durkheim in his theory does establish the universality of suicide but presents inclinations of people across diverse background to suicide. Drawing from statistics, Durkheim's famed study explored causal factors from a psychic and cosmic perspective, and its transferability by means of imitation. The study of factors demonstrates that neither psychopathic, heredity, climatic, financial or personal factors on their own could form an adequate explanation of suicide. Through seeking the states of the social environment - religious, family, 
occupational groups, and political environment - Durkheim explored how they intersect with suicide. Significantly the study sought the determination of the social types of suicide through classifying them by the causes that produced them and the social conditions responsible for them.

Durkheim's classification of the types of suicides is done based on different types of relationships occurring between a person and their society. As a précis, four types of suicide emerged from Durkheim's work. "Egoistic suicide" bears from the circumstance where a person becomes socially isolated, plagued with the feelings of moral irrelevance in their society, and the struggle to align. Secondly Durkheim posits that "Altruistic Suicide" occurs among persons belonging to social groups that are marked by strong social integration: an intimacy and closeness that enable the loss of individuality. Characteristically occurring among primitive people, Durkheim offers examples of the sati immolation traditions of India for insight. Durkheim's third classification is the "Anomic Suicide", occurring as a result of a collapse of social equilibrium; marked by considerable excitement due to stress or frustration from, for example, bankruptcy. This is born out of a low degree of regulation. In contrast to anomic suicide, "Fatalistic Suicide" therefore occurs as a result of extreme level of regulation an individual lives under. Marked by high expectations set by their society, this type of suicide occurs characteristically amongst enslaved persons who are typically over-regulated.

\section{LITERATURE REVIEW}

In studies pertaining to suicide, its aetiology and morphology, Durkheim's theory of suicide continues to serve as an operative framework. It has been explored extensively by studies to establish diverse nature of suicide across board (Abraham 2015; Manning 2012; Pape 2006; Stack 2004; Zevallos 2006). Manning (2012) in relation to Durkheim's theory further classifies the four social conditions that encourages self-inflicted death. According to him, suicide can be marked by very low or very high social integration and very low or very high moral regulation. Basically, it could be accessed on the dual scale of social integration and moral regulation. Stack (2004) also expands the understanding of the features of Durkheim's theory. Aligning with Durkheim, he postulates that the principal loci of altruistic suicide are primitive societies, and that it typically benefits social order. Altruistic suicide is also marked by cultural approval and occurs in social groups where communalism trumps individualism through excessive integration of the individual. Persons who conduct this type of self-inflicted death are projected as being very close to their cultural beliefs to the point that they lose their individuality or de-emphasize it.

People that engage in self-immolation, perform it for something they love beyond themselves. Although Durkheim did not explicitly refer to self-immolation at the time of writing, clear links exist between its understanding and Durkheimian logic (Uzzell 2012). Under Durkheim's theory, when an individual or group of persons self-immolates, it is classified as an altruistic suicide, and understood as a socio-political act to advance a cause. Such socio-political acts are affirmative acts, an underlay of protest suicide.

\section{PROTESTS AND SUICIDE}

Fahlenbrachet et al. (2016) posits that protest is presented as an ubiquitous phenomenon which is no longer limited to the spaces of civil societies and political societies, but have expanded to include the participation of grassroots initiatives, artists and more importantly individual citizens. This shift extends to the morphology of protests, the performance of it and the spaces that are employed. Their work offers a cultural study dimension for understanding protest culture in general as a form of challenging communication through employing diverse media 
and strategies. Performed in either public or private spheres, everyday life or the cyberspace, expressive forms of protest have become integral to social lives. People are articulating their dissents in more expressive forms through their bodies, their fashion, dance, graffiti, as well as the creation of alternate media platforms, posters, songs and other communicative forms. Silence has equally been considered as a form of protest (Al-Aghberi 2015). The cultural functions of the above forms of protest communications expand the analytical perspective of protest movements.

The perspectives of protest phenomena is widened to cover various cultures of dissent across the world, but issues of self-application of lethal violence is not a focus in the forms or mechanisms for protest explored. The study objectives of Fahlenbrach et al. (2016) may not favor a heavy concentration on protest suicide, but we find it important in presenting the broad spectrum of different protest agents, thus proposing that organizations should have no monopoly, and the individual - who is a subject in our study - is formally included. Likewise, the human body is acknowledged as a tool in the protest culture. Makley (2015) in his work draws attention to the efficacy of the body, especially in death, advancing the idea that dead bodies are key sites for rethinking politics.

Of greater value to this study is the position of Abraham (2015) in situating selfinflicted death as a protest mechanism. Using real cases of protest suicides to contextualize protest suicide, her work focuses on protest suicides that highlights oppression and influence collective action for social justice and change. In presenting her thesis, she classifies protest suicide into two types. There is public protest suicide which is largely enacted in public spaces, drawing attention to the actor and the oppression they represent. The second is the privately committed suicide which owing to the sheer cumulative number of the actors who have engaged in it on the grounds of shared grievance, obliges society to take note of their issue. Her work highlights some distinctive features of self-immolations and draws attention to the outcomes; essentially the problem of oppression, its impact on the actors and the trajectory of the public responses.

Several studies highlight the importance of looking at suicide as a protest mechanism (Biggs 2012; Manning 2012; Uzzell 2012). Manning (2012) in his study notes that consistent with other acts of deviance, suicide may be a way of expressing grievances. Aligning with Durkheim's position on the altruism in self-inflicted death, Uzzell (2012) notes that some forms of suicides are clearly acts of altruism, serving as a way of helping others. All these studies offer justification for the conceptual validity of suicide as a protest mechanism. Furthermore, they give an additional grounding for our study.

\section{THE WRITER AND HIS WORK}

In this study, we have selected the work of a contemporary African writer, Chuma Nwokolo, for his communicative uses of death and the relevance of suicide as a theme. Foster (1964) in referring to the uses of death in novel, note that writers find it congenial, as a way of ending a book very neatly. The death of a character in a novel is often a way to end the role of that character, but in the works of Chuma Nwokolo, characters die to live. Dying for most of the characters becomes a powerful means of communication, drawing attention to causes or issues that burdened their lives. Dying is adopted by Nwokolo as an act when something more than words is needed. His characters are fearless, they are not afraid to die for causes they believe in. The character of Treeman in Nwokolo's The Ghost of Sani Abacha (2012) further validates this when he is threatened with death by a rampaging bulldozer. Treeman's faith in protecting the Badforest which holds together the ecosystem of the Waterside community and saves them from deforestation, keeps him standing until he is crushed. 
Literary spaces are used to highlight protests (Zeiny 2019), and Nwokolo's works make good contribution. We adopt specifically the most recent work of Chuma Nwokolo: The Extinction of Menai (2018) to explore incidents of self-inflicted deaths as a protest mechanism. In this novel, language and culture loss is a central theme. Set across the continents of Africa and Europe, this novel focuses on the Menai people from Kreektown in Nigeria's Niger Delta. The Menai ethnic nation are descendants of the historic Meroe civilization. The global population of the Menai is reduced to just hundreds and is further threatened by each new death. Readers are caught up in the cycle of deaths. There are no stories of marriages, and only in the end of the book will a reader witness a birth. Thus, it is a story of the Menai and their struggle against their impending extinction.

We therefore conduct a close reading of the aforementioned work of Chuma Nwokolo to explore the concept of self-immolation. In studying this novel, we understand the challenges of determining the exact cause of a self-inflicted death in the absence of suicidal notes. Bearing in mind that in the events of suicide, not all characters leave suicide notes, we adopt the use of the character's revelations of their conditions to characterize the motives of suicide. We therefore look at their antecedents, their material environment, moments where the resolve is formed, the preparations and the performance of suicide for our analysis and conclusion.

\section{WAYS OF DYING IN THE EXTINCTION OF MENAI}

A British company, Trevi Biotics, conducts an unauthorized drug trial during an outbreak of Lassa Fever. No Menai is affected by Lassa Fever, but with the help of their son Tobin Rani, the Trevi team led by Felix and Laura Fraiser uses the Menai as Rhesus Monkeys, unethically injecting them with the experimental vaccine. The Trevi vaccine with its prolonged side-effect results in a spike in nephritic diseases and sterility which sentences the Menai to death. The lives of many Menai who are now dispersed from their home in Kreektown as a result, begin to evolve in a chain of interconnected events anchored on their struggle for survival, reestablishing their identities and being whole again.

In The Extinction of Menai, the word "suicide" is first mentioned in the prologue, and then first featured in the profiling of the character of Dalminda Roco, through his introductory conversation in Humphrey Chow's sustained hallucination. He patiently introduces himself; "A suicide bomber! That's what I am" (p.23). His introduction as a suicide bomber sets the stage for the utilization of suicide as a concept in the novel. With the word "bomber" attached to suicide, the means of suicide is depicted, with the aggravation it potentially provokes. Dalminda Roco is aggrieved by the death of his father who suffers bankruptcy, resulting in a heart attack. His depression from the suffering following his father's death and anger towards a society that made no provision for people who fall through the cracks, leads him to settle with suicide bombing as a gainful way to die.

While Dalminda Roco lived in Humphrey's hallucinations, on the other side, members of Menai society also begin to die and gamble with death, owing to the rogue drug trial of Trevi which they have become victims of. At the beginning of the book in the year 1990, the Menai had an extant population of 1,160 members (p.5). At the end of the book in the year 2005, the population had dropped to 24 (p.369). A timeline of these deaths shows the occurrence of about 600 deaths in a decade; for example the Menai population suffered a drop from 1,160 in 1990 to 430 in 1999:

The Menai started dying. People had started grumbling that the Menai health Centre had not delivered a single child since 1980. Then they noticed a spike in nephritic cases. We started dying in 1985 . Ugom was the first to go... 1990 was the year that six children died in a day. That was the year of Ma' Bamou's Topless procession. 
It was not only the bodies of the Menai that died, but with every death in Menai their language, cultural values and practices began to die too. One of such values was their value for life; they were greedy for life. The Menai did not count a person of 50yrs as old enough to die, it was to them a curse, death was only allowed at the age of 110yrs. As the Menai became a land of death and no birth, it is remarkably not just those whose bodies had failed as a direct consequence of the Trevi's planned genocide that die, but those who chose to accelerate death by suicide.

Durkheim characterizes altruistic suicide as occurring among primitive people who belonging to closely knit society with an intimacy and closeness that enable the loss of individuality. This social conditioning is consistent with the Menai and foregrounds the suicides that occur. Among the Menai, Jonszer is the first to practice such self-inflicted death. His death and way of dying is significant because unlike the other Menai, Jonszer is one of the few to have escaped the Trevi inoculation. They had not bothered to waste their precious vial on a drunk. Like all Menai who are pathologically averse to city life owing to an indoctrination that discourages their migration out of their village, Jonszer remained in Kreektown. He witnessed the transformations and death of his culture. Although he suffers an addiction of alcohol, Jonszer is sober enough to appreciate the realities of his society. Jonszer is introduced at the beginning of the book as the local guide to Chief Dr. Ehi Fowoka; the self-acclaimed Menai expert. It is evident that Jonszer's knowledge of his culture and his people is reliable. The structure of Kreektown, the people and the custom are overwhelmed by the imminent extinction. Kreektown is now full of empty houses, the fabric of the Menai was long fading, it does not spare their governance system, Menai's Mata Nimito who is called the philosopher guide of Menai was no longer the symbolic leader he used to be. He had no Menai left in Kreektown aside Jonszer. The strangers who now occupied the empty homes of the dead and dying Menai had no value for Mata Nimito beyond the monikers "Hundredyears" and "the Chief of Dead People" (p.57). It is with this lack of understanding that the strangers announced the false death of Mata Nimito to Jonszer, provoking his grief. The glue that bonded Jonszer to Menai, the anchor to his self-identity was gone. Jonszer could not bear to be the last Menai, he could not bear the complacence with which the world dealt with the injustice done to the Menai. The news of Mata Nimito's death, which should have been a table sweeper anytime is treated as a beer parlour raucous talk, announced by the voice of mocking strangers. To see the indignity given to the highest authority in Menai was for Jonszer the last straw. Words were not enough to communicate his anguish for the extinction of Menai, perhaps a provocative act of a tabooed self-application of lethal violence sufficed. Zanda who witnesses Jonszer's last moments narrates it:

\footnotetext{
Then I looked down and there, in the midst of the rapidly filling courtyard, saw Jonszer.

He had bloodied dagger, and people gave him a wide berth. A length of rope was fastened to his ankle. He leapt, pranced, screamed like one demented, hacking at his body with his blade; as I stood there, open mouthed in the window, he stooped and pointed his broad knife at me.

'MiyakasiaMenai!' In that moment I saw his grief and pain... A few seconds of silence ensued, and then he resumed, his voice hoarse, unrecognizable, fading away in the direction of Kreektown Square. In moments the yard was silent, and I knew the crowd had followed him...

"He drowned himself! Just like that! They said he tied his foot to the underwater root!

How's that even possible?"

Jonszer defines protest suicide with his final words: "'Miyaka sia Menai... See what's left of Menai!" (p. 74) He chooses his way of dying, making it performative, a protest drawing attention to the injustice done to his people. He inflicts harm on his body in public display, and further refuses to save himself, despite being an excellent swimmer like most Menai. He "dived into a creek with a cord and roped himself to the mangrove root under the surface" (p. 77). Jonszer's death becomes the first protest on the death of the Menai culture in the sequence of 
the novel. His level of cultural awareness enables him to understand the implications of his mode of death. The finality that Mata's death brings provokes his choice of suicide, thereby falling foul of Menai's great taboo.

Consistent with Durkheim's characterization, Chief Dr. Ehi Fowoka presents the Menai as primitive: "Menai ethnic nation manifests an insular clannishness" (p. 3). His narratives portray the Menai culture as an elaborate social mechanism of a primitive society which is used to corral the poor members into communal compliance. Although Dr. Ehi Fowoka records in his monograph on the Menai, that the Menai had no word for suicide, their lack of vocabulary for him meant that it was not a part of their culture. But in the mechanism of the Menai culture, suicide was a taboo. Weaver Kakandu refers to it as "the great taboo that has no name" (p. 329). The word Kamogo existed in the Menai vocabulary, both the word and the act itself was a taboo since the time of the Crown Prince Alito. In the history of the Menai as captured in their funeral history song, Crown Prince Alito is recorded as the first to commit suicide in protest to get justice for the betrayal of the Menai. But their imminent extinction provokes many Menai to consider or engage suicide, as an altruistic act to amplify the voices of their struggle.

In his reflections of the tragedy that Menai was fast becoming, Farmer Utoma likens the living Menai to his chickens in their cage. His difficult walks around his compound is associated to the way chickens walk around in their cage. Behind his poultry sheds, the smell of spoilt crates of eggs which he couldn't sell reminds him that his customers had died before the chickens. His envy for the dead; his friends and families who are now in the circle of the Menai ancestors, is expressed. He feels strongly the need to die but his knowledge of the taboo that suicide is deters him:

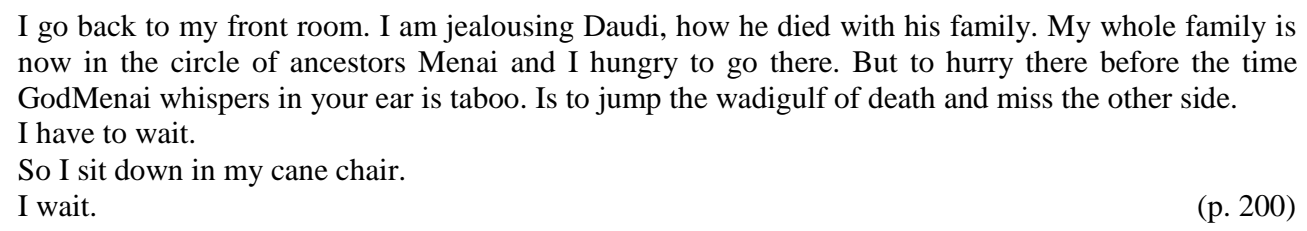

The Tandama, the music of the Menai's treasured xylophone is not played for those who commit suicide, they will be buried in less honorable way than those who waited on God's time. Unlike other Menai rulers, Crown Prince Alito who killed himself is not buried with a Bronze Singateya. However the sacrilegious value of suicide had become compromised by the injustice that condemns their culture to extinction. The Menai who are sworn to peace and nonviolence are adopting the most lethal form of self-violence.

Bamou Geya the Menai who finds himself in the four walls of the Cote d'Ivoire prison, is troubled by the nonchalance with which the world treats his people's fate. His decision to work as an intern for CITES project breeding the rare white-naped mangabey monkeys for reintroduction to the wild is inspired by the parallel between his endangered Menai and the animals. His first protest act to draw attention to his endangered ethnic nation gets him a 15year prison sentence:

He was in the Primate Camp that evening when news of the Topless Procession came through the radio.
One of the six dead children was his daughter Felimpe. It was the loss of daughter, the disconnect
between the care and expense invested in monkeys and the world's indifference to the extinction of his
ethnic nation that drove him into a five-minute fit of madness with a handy machete. He would spend
the rest of his life ruing the death of those two dozen mangabeys in his frenzied slaughter.
(p. 213)

But it is his selfless act of suicide that brings attention to the indifference of the world to the plight of his people. Bamou's way of dying and his life story puts the Menai in the global 
spotlight. Humphrey who is part of the prison censor team details the last moment of Bamou's life:

\footnotetext{
While I cleared my desk, he read a few lines and then let out a roar that was more buffalo than man. He rose, threw my heavy desk across the room with a sweep of the hand, and charged at the far wall, head lowered like a battering ram!

That was my last clear memory from that life. My friend, Bamou, the pleasant Menai who did not have a single enemy in the world - bar the ghosts of his hapless mangabeys - went from a man looking forward to his release within the fortnight to a convulsing body, bleeding from head fractures as he died on my office floor.

(p. 214)
}

The message from Bamou's sister Rubi announcing the death by suicide of their mother Ma' Bamou provokes him into self-application of lethal violence, "he just jumped up and brained himself!" (257). While Bamou's death is not planned, it is clearly provoked by a buildup which is cemented by his mother's suicide. It is unclear if Bamou had pre-meditated his suicide, however his antecedents are revealing of his efforts to defend his communal identity, by protesting the indifference of the world on their plight. Ma Bamou's suicide however becomes a performative act. As with other Menai, to die for their ethnic nation, becomes a longing they share. As Farmer Utoma envies Daudi, Ma'Bamou is envious of her husband who pre-diseased her three weeks earlier: "Namodi is more lucky, that he has die already" (p.341). Her antecedents show a deep grief for Menai, the loss of the life she once had as a renowned trader in Kreektown, and a son, Bamou, whose fate was uncertain. A daughter Rubi who by oath to her faith will never bring forth a child and an only grand-daughter Felimpe who lay joined by her husband Namodi only three weeks ago, beneath the floor of her bedroom in eternal sleep.

The Menai had no value for individualism, they were tightly knitted to their land in Kreektown, in life and in death. The government's response to their condition was taking them against their will to isolated dormitories in faraway cities. The sight of soldiers dragging the Menai out of their houses to the dormitories is an indignity that Ma'Bamou will rather die than bear. Comparatively, she finds what is happening to the Menai worse than all she had seen during the Biafran civil war:

That is one disgrace that would have killed me, true: for soldiers to drag me from my own house to take
me to a government dormitory. Something I did not see, even during the civil war. Is better for me to
go for one-week holiday... Or two weeks even. (More than that, may GodMenai forbid). Because for
many day's now they have been going street to street, catching human beings like fowls.

The indignity of this humiliation of the Menai value was unfamiliar in the repertoire of Menai culture, neither was the response. Leaving their communal lives in Kreektown with some dignity was better than being taken forcefully like a fowl. Ma' Bamou commences on a familiar journey to Lagos, she leaves her house, leaving Kreektown, this time "maybe for the last and final time" (p.338) with a strong conviction that she may not return, as returning to a broken Menai alone was worse than death. Saying goodbye and provoking avoidable tears was for her a foolish thing, she preferred to leave on her own terms. The path to Lagos affords her the space to reflect on a critical incident instigated by her which put the story of injustice done to the Menai on the global Map. On sighting the memorial built for the six Kreektown children, it may have felt like a worthy remembrance for the protest she championed for her dying ethnic nation. She reminisces on leading a Topless Procession to the governor's office, carrying the cold body of her grand-daughter Felimpe, joined by mourners who carried the bodies of five other Menai children. Burying their children was for her, tantamount to the death of the Menai; "And are we not all dead, O Menai, that bury our children before ourselves?" (p. 340)

Central to Ma Bamou's last moments was her deep grief over the loss of the Menai culture. Her grief is deep and she chooses to bear it alone, it could be imagined that if her 
renowned protest to the governor's office could offer no relief then sharing her pain wouldn't either. "Today, I just smile and keep quiet, to hide the pain from my friends, because what can they do for me, except to say "sorry" and feel bad too?" (p.341). Culture shock further aggravates her, she misses the Kreektown village where communalism trumps individualism, Kreektown houses had no walls as the ones in Lagos; "The Lagos walls are the hardest things. Kreektown doesn't build walls. For what are we building it?" (p.342) She misses the Menai language which was now endangered:

And one thing I want more than anything is to sit in a market where my maybebuyers will say to me, 'Worie,' instead of 'Good morning,' and I will answer 'Dobemu.'...But all I'm doing, everyday in Lagos, is speaking this English like a stammerer.

The struggle of imitating language and culture in a space (Dwyarie \& Tjahjani 2019) is expressed by Ma Bamou. Her visit to the Menai children who have been moved to dormitory in Lagos is a critical incident that leads to her final moments. The prison-like walls around the hostel where the Menai children are kept troubles her; that the children have become acculturated to the point of forgetting their Menai water toast tradition further raised her concern "we hug and greet and hug and greet and cry a little... but nobody brings water to greet us in the Menai way. Is not many weeks they left Kreektown and they have forgotten already?" Her motherly concern for her endangered Menai further registers in the way Asiama now speaks Menai; "already her Menai is becoming heavy on her tongue..." (342). Ma'Bamou is oblivious of the fact that just like her, the Menai children suffered culture shock too. In their own way the younger Menai struggled with their isolation from the only village they had known all their lives, their communal space was a strong string to their sense of well-being and identity. Nothing symbolized their struggle more than Masingo's gamble with death near the Lagos dormitory. As Ma'Bamou narrates:

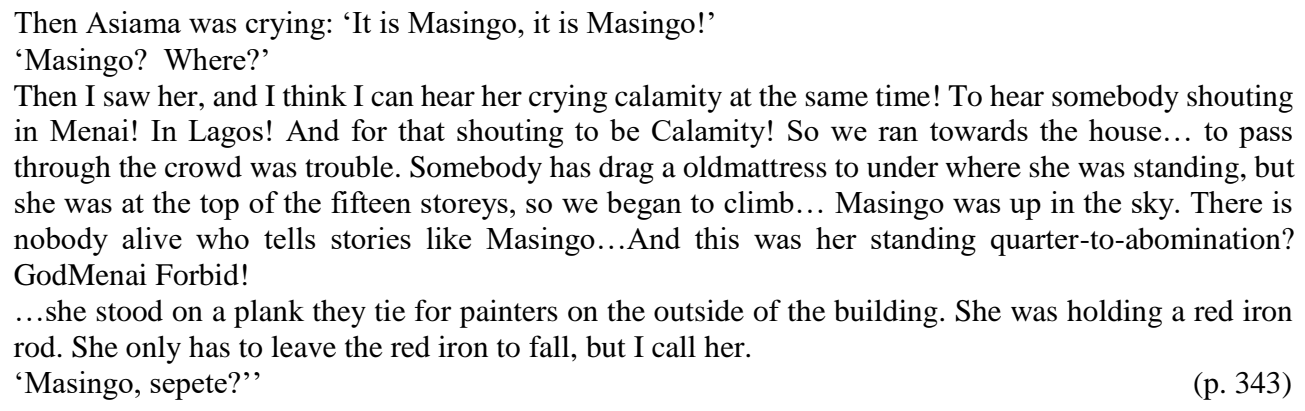

Masingo shows the pains of poor integration caused by the forceful relocation of the Menai who were culturally averse to city life and intricately knit to Kreektown. The culture shock of living in isolation from the only home she identified with and the prolonged tragedy of her people leaves her with a sense of despair. In despair she tries to find her way back to Kreektown: "She left the dormitory, but she didn't know her way back to Kreektown. In all the motor parks she went, nobody even know the name 'Kreektown' or the people call Menai!"(p.343) Ma' Bamou could relate with the pain of forced migration for a first timer; the struggles of the small-town girl who is forced into a big city with no briefing. Unlike Masingo, she knew that Lagos was not as small as Kreektown and Ubesia with one or three motor parks, that no one spoke Menai in Lagos and that a Menai who didn't speak English would be lost. But this was Masingo who had never left home before. Her loss of community, leaves her with an unfamiliar sense of isolation: 
'You're not, Masingo. See, I'm here as well! And Asiama is here as well.'

'We're not enough!'

Masingo's sense of loss drives her to organize a suicide. To save her from the mouth of death would require offering a counter-narrative, and this is what Ma'Bamou does with her elderly wisdom. "Because that is what adults do, O Menai: tell the little lies to the children until they are old enough to know that life is war itself" (p. 343). She offers hope to Masingo, assuring her that Menai now had a future after all. Masingo takes the offer to live again to the applause of spectators. In saving Masingo the Menai's best storyteller from suicide, Ma' Bamou consciously swaps place with her and takes the fall in public glare with a prayer that she succeeds in dying. Her last words are damning; in holding Masingo's hands and leading her back to life, she longs to hold them again before her own conscious taboo death. "Anobi, anobi, anobi..." (p. 343) Masingo thanks her for a second chance at life; "But why is she thanking me?"'Ma'Bamou does not receive the thanks for she knew she could never thank Masingo for offering her a desired stage for a protest suicide:

O Menai! To hold them one more time, before I become a taboo ancestor who will never fellowship
with GrandMenai!... strange languages wash over us like dirty water, enough to comfort Masingo today
and for tomorrow. But I do not want to see her face when she knows that I lie to her. That I lie to her in
the name of GodMenai.
I feeling warmer than I ever feel before, like a woman that has given birth. But this is the fate of women:
sometimes we die in childbirth. Like Bamou's wife. I let my walking stick fall. The iron cries on
concrete. It does not hit the mattress. By the grace of GodMenai, me myself, I won't.

As with the selfless ways of a mother, Ma Bamou gives up life with her last breath. She rejects life for herself, in pursuit of a selfless cause. Masingo's rebirth orchestrates Ma' Bamou's death, fulfilling her longing to join her ancestors. Significantly as it was with her days as the leader of the renowned Menai topless procession protesting the injustice done to her people in public, it is little surprise that in choosing a way of dying, she takes advantage of a staged public protest suicide to give voice to the pain of loss which they had long borne alone. Aloneness, the loss of community remains consistent in the lamentations of the Menai who commit suicide or gamble with it. Like Masingo, Weaver Kakandu also expresses his lonesomeness as a Menai in the vastness of the world. Their loss of community is hinged on the organic solidarity and the neighborly orientation all Menai had been socialized to have. The grief for the eclipse of their local territorial community in Kreektown is worsened by their forced migration; unprepared separations and injection into big cities where they are poorly integrated. Kakandu the last Menai weaver mourns his daughter; her death implies that there will be no transgenerational transfer of the skills for making the Jamaya. He shares his lineage of artisanship in the ways they had learnt to pack the Jamaya; "the way my father taught us, the way his father taught him, the way I taught my ancestor-daughter" (p. 327). Although extinction was looming over the whole Menai ethnic nation, for Kakandu extinction had happened on him; he was the only surviving member of a family of weavers. Salia's death spelt doom; the hope that the Menai weave will survive another generation was gone. The effort of the government to protect it from dying out with Kakandu and his ethnic nation felt like torture to Kakandu, some things just ran in the bloodline only and could not be formally taught: "Before my legs grew long enough to pedal a Jamaya, I used to sit and watch my father whose hands were the fastest in Menai...throw the koma and listen to the song"(p.326). He bewailed the loneliness that now loomed over his family heritage; the fate of his expertise: "Me that am expert in many different designs of marriage cloths, but for many years now, is only burial shrouds that I weave" (p. 326). But it is his fate as the last Menai that haunts him most, to imagine that in death he will be dishonored, his body will not be wrapped with a shroud, he will be denied the melody of the Tanda ma like all Menai: 
I spend my life making cloth that my customers will never see. I am weaving food for termites. The fellowship of the kamira is broken. It is a long time since I knew that as the last weaver, I Kakandu, master weaver of Menai, will not have a burial shroud himself... but now that the last Mata has died, who will play my Tanda ma?

(p. 328)

The prospect for him to die honorably was poor, there was nothing to gain in waiting until GodMenai called him, whether he waited or not, a dishonorable death awaited him. Neither the voice of the Mata or the taboo of a dead culture could restrain him:

I cannot go back to the loneliest sound in the world, the sound of one Jamaya. Especially one that goes
chaka-cha chaka-cha. I won't stutter anymore or wait for the rabbit to eat his fill and close Menai's last
kamira... There are more important things, like the voice of the girl. She is hawking bread, she is too
thin to be Salia, but it is Salia's voice so I follow her... Salia! I still remember the weight of her as I
laid her down in her bedroom grave... although I know it is not her, it is good dream...Because only
my daughter can call me into the wadigulf of the great taboo that has no name...
Then I hear Mata Nimito's voice singing in my head and I freeze...the weight of taboo presses me,
heavy, heavy, I cannot breathe. Mata Nimito's skies reads my mind, they frown on me. I am hot.
GodMenai! There is no shelter from his searching gaze, from the knowledge of
ancestorsMenai... Mata's voice dies away.
Who will sing my tanda ma? I that have shrouded hundreds of Menai in their graves, who will shroud
me, the last Menai? For what am I living now? May God Menai forgive my sins... I am running to
comfort her through the doorway of a running lorry.
(pp. 329-330)

Weaver Kakandu dies in a flight of fancy, he runs after a girl he wants to believe is Salia, his dead daughter. Prior to that he bemoans his fate and is further left in despair by the lack of hope and effective response by the government to ensure the Menai survives. The darkening power of this colossal loss grips him. His hallucination that follows were purposeful, he silences the voice of reason and instead hurries to commit suicide. He runs to comfort his dead daughter through the doorway of a running lorry.

\section{CONCLUSION}

Through a close reading of Chuma Nwokolo's The Extinction of Menai, we establish the uses of suicide by characters in the novel. Emile Durkheim's theory on altruistic suicide, the social integration locus provides a backdrop, offering a lens for understanding this study. Consistent with his classifications, we find that the characters in this novel exhibit behaviors that express their very strong social integration, an intimacy and closeness that enabled the loss of individuality. The principle loci of the altruistic suicide is the fact that the performers emerge from primitive group, just as the Menai who have been referred to as an atavistic society. Undoubtedly the Menai had powerful internalized beliefs and a collective identity. Individualism was a strange concept and their feelings of aloneness or any threat to their organic integration further triggered suicide ideations.

We establish that there is a cultural underpinning that drives each suicide. Although the trends of suicide exhibited by some characters in the works of Chuma Nwokolo might be interpreted as similar, despite their similarities, there are significant variations. Abraham (2015) in her studies categorizes two types of protest suicide. The first type is enacted in public as is seen in the performative suicide of characters like Ma'Bamou and Jonszer drawing attention to the injustice that the characters present. The second type is one that may be solitary and private but by the sheer cumulative number of persons who have engaged in it, the society is obliged to notice their cry for justice. The aggregate number of characters who gambled with death and those who executed self-inflicted death in The Extinction of Menai forces the attention of readers on the injustice they represent as highlighted in their last words.

Nwokolo further widens the scope by making the act of self-immolation gender inclusive. Female characters like Evarima Udama and Masingo gamble with death. Ma'Bamou 
who engages in a performative suicide show that consistent with the theory and other studies, the act of protest suicide cuts across gender. In presenting a narrative where Bamou takes after his mother Ma'Bamou to engage in suicide, the question on whether suicide could be an imitative behavior or if it holds a trans-generational element is raised.

Through our study of this work of Chuma Nwokolo, further insight on self-immolation is gained. Self-immolation can be viewed from a sociocultural lens; this is valid considering that characters who commit protest suicide exist in a cultural system where they have been socialized with certain expectations. These expectations thus foreground the sense of violation or oppression felt by the characters that trigger the need for protest. Additionally, where their moral or material environment does not provide justice, it leaves them with a sense of devoicing; a feeling that no one hears or sees their pain. To amplify their voices, selfImmolation; the most extreme form of protest, therefore becomes their only choice.

\section{REFERENCES}

Abraham, M. (2015). The Intersections of Protest Suicides, Oppression and Social Justice. Sociologies in Dialogue, 1(1).

Achebe, C. (2009). Things fall apart. Toronto: Anchor Canada.

Ahmadi, A., Mohammadi, R., Stavrinos, D., Almasi, A., \&Schwebel, D. C. (2008). Self-immolation in Iran. Journal of burn care \& research, 29(3), 451-460.

Al-Aghberi, M. A. (2015). Telling the Untellable: Dialectic of Silence in Jewish-American and Arab-American Holocaust Discourse. 3L: Language, Linguistics, Literature ${ }^{\circledR}, 21(1)$.

Biggs, M (2012).Self-Immolation in Context, 1963-2012. Revue d'Etudes Tibétaines,no.25, 143-150. http://himalaya.socanth.cam.ac.uk/collections/journals/ret/pdf/ret_25_12.pdf

Biggs, M. (2006). Dying without killing: Self-immolations, 1963-2002. Making sense of suicide missions. edited by Diego Gambetta: Oxford University Press, 2006, 173-208.173-208.

Browne, M. W. (1965). The new face of war. Indianapolis: Bobbs-Merrill.

Dwyarie, R. D., \& Tjahjani, J. (2019). Intercultural Concepts in Place Cliché by Jacques Godbout. 3L: Language, Linguistics, Literature ${ }^{\circledR}, 25(3)$.

Durkheim, E. (1951). Suicide: A study in sociology. New York: The Free Press.

Fahlenbrach, K., Klimke, M. \& Scharloth, J. (Eds.). (2016). Protest cultures: A companion (Vol. 17). Berghahn Books.

Forster, E. M. (1964). Aspects of the novel. Harmondsworth: Penguin Books.

Friesen, A. R. (2006). Okonkwo's suicide as an affirmative act: do things really fall apart?. Postcolonial Text, 2(4).

Krishnamurthy, B. (2016). Rebirth of Self and Identity: An Analysis of Meena Alexander's Manhattan Music. $3 L$ : Language, Linguistics, Literature ${ }^{\circledR}, 22(2)$.

Makley, C. (2015). The sociopolitical lives of dead bodies: Tibetan self-immolation protest as mass media. Cultural Anthropology, 30(3), 448-476.

Manning, J. (2012). Suicide as Social Control 1. In Sociological Forum. Vol. 27, No. 1, pp. 207-227. Oxford, UK: Blackwell Publishing Ltd.

Nwokolo, C. (2018). The Extinction of Menai: A Novel. Ohio: Ohio University Press.

Nwokolo, C. (2012)Ghost of Sani Abacha. Lagos: County Books.

Ogbaa, K. (1981). A cultural note on Okonkwo's suicide. Kunapipi, 3(2), 13.

Pape, R. A. (2006). Dying to win: The strategic logic of suicide terrorism. Random House Incorporated.

Romm, S., Combs, H., \& Klein, M. B. (2008). Self-immolation: cause and culture. Journal of burn care \& research, 29(6), 988-993.

Ryan, K. (2000). Revolutionary suicide in Toni Morrison's fiction. African American Review, 34(3), 389-412.

Shakya, T. (2012). Self-immolation, the changing language of protest in Tibet. Revue d'étudestibétaines, 25(2012), 19-39.

Stack, S. (2004). Emile Durkheim and altruistic suicide. Archives of Suicide Research, 8(1), 9-22.

Uzzell, J. (2012). Biopolitics of the Self-immolation of Mohamed Bouazizi. e-International Relations, 7.

Zeiny, E. (2019). Ecriture Feminine: Feminism and Nationalism in Seyyedeh Zahra Hosseini's 'One Woman's War: Da'. 3L: Language, Linguistics, Literature ${ }^{2}, 25(3)$.

Zevallos, Z. (2006, December). What would Durkheim say? Altruistic suicide in analyses of suicide terrorism. In Sociology for a mobile world: Proceedings of the Annual Conference of the Australian Sociological Association (pp. 1-11). 